\title{
Validation of family planning tool in the pastoralist community
}

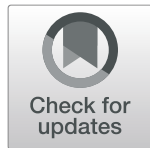

Mussie Alemayehu ${ }^{1 *}$, Araya Abrha Medhanyie ${ }^{1}$, Elizabeth Reed ${ }^{2}$ and Afework Mulugeta Bezabih ${ }^{1}$

\begin{abstract}
Background: Pastoralist community, Afar, women felt that they are embedded in strong cultural and religious perspectives which promotes a high number of children, and discourages family planning (FP) use. They are multifaced factors which hinder women not to use FP and it is time to develop a context-based tool to understand the situation at the ground. However, we have a dearth of evidence on a reliable and valid tool. Therefore, this study aims in developing a reliable and valid tool that considers the women's knowledge, male involvement, attitude, and belief about whether most people approve or disapprove of the behavior to use or not use of FP.

Methods: A total of 891 married women participated in the study. Reviewing the literature, piloting, pretesting, and collecting the actual data were the steps we used to develop a reliable and valid tool. We used the integrated behavioral model (IBM) as a conceptual framework for developing the tool. The developing tool consists of 1) knowledge 2) perceived male involvement and 3) constructs of integrated behavioral model (IBM); expressional and instrumental attitude, subjective norm, self-efficacy, perceived control and intention to use of FP. The IBM items composed of direct and indirect measurement. In the analysis of the data, exploratory and confirmatory factor analysis was done. Independent t. test with cohen's d was used to calculate the effect size. The correlation coefficient was carried between the direct and indirect measurements of the items of the integrated behavioral model (IBM).
\end{abstract}

Results: A total of 891 pastoralist married women were included in the analysis of the reliability and validity of the tool. The mean age of the participants was $26.74( \pm 6.45)$. The KMO value for all items was greater than 0.83 with a Bartlett test of sphericity of $(p<0.00)$. Thirteen items were used to measure the knowledge of the respondent towards FP use. The tool had 64.92 variances explained and Cronbach alpha of 0.85 . Acceptable values of the fitness indices were obtained in the confirmatory factor analysis (CFA) The items of knowledge towards FP had normed chi-square of 4.5, RMSEA with $90 \% \mathrm{Cl}$ of $0.064(0.056,0.071)$, SRMR of 0.039 , CFI of 0.969 and TLI of 0961. All the developed items had a Cohen's $d$ ranges from 0.5 to 2. Moreover, the correlation test of the IBM ranges from 0.6 to 0.7 which shows a higher correlation between the measurement direct and indirect items.

Conclusion: The pastoralist community version of the FP questionnaire is a valid and reliable tool and can be used to measure future family planning use. The indirect measurement of the IBM constructs was a good item to measure FP. However, as a limitation of the study respondents may face difficulty in realizing the difference one item to another especially when items on the scale look so similar to her.

Keywords: Afar, Attitudes, Confirmatory, Contraceptive, Exploratory, Family planning, Married women, Pastoralist, Reliability, Validation

\footnotetext{
* Correspondence: mossalex75@gmail.com

'School of Public Health, Mekelle University, College of Health Sciences, Mekelle, Ethiopia

Full list of author information is available at the end of the article
}

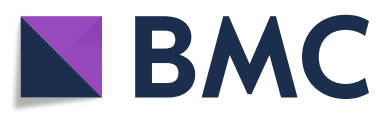

(c) The Author(s). 2020 Open Access This article is licensed under a Creative Commons Attribution 4.0 International License, which permits use, sharing, adaptation, distribution and reproduction in any medium or format, as long as you give appropriate credit to the original author(s) and the source, provide a link to the Creative Commons licence, and indicate if changes were made. The images or other third party material in this article are included in the article's Creative Commons licence, unless indicated otherwise in a credit line to the material. If material is not included in the article's Creative Commons licence and your intended use is not permitted by statutory regulation or exceeds the permitted use, you will need to obtain permission directly from the copyright holder. To view a copy of this licence, visit http://creativecommons.org/licenses/by/4.0/. The Creative Commons Public Domain Dedication waiver (http://creativecommons.org/publicdomain/zero/1.0/) applies to the data made available in this article, unless otherwise stated in a credit line to the data. 


\section{Plain English summary}

Women in the pastoralist community are double marginalized as being women and pastoralists. In an area where the married women embedded in a strong cultural and religious perspective which promotes a high number of children and discourages Family planning (FP) use, developing a tailored and context-based reliable and valid tool would be vital. The health indicators of maternal health including FP was very far for the pastoralist community including the Afar region as compared with the national average. For instance, according to the Mini Ethiopian demographic health survey (EDHS), 2019 the Afar region was FP coverage was $12.7 \%$ while it was $41 \%$ for the national coverage. The most common reason mentions for not using FP in the region was lack of awareness among the women, husband objection, and religious perspectives which promotes a high number of children and discourages FP use. And, developing reliable and valid FP tool which considers the local context would be timely. Hence, we made a reliable tool using reliability test, exploratory and confirmatory factor analysis. However, as limitation of our study goes the respondents may face difficulty in realizing the difference one item to another, especially when items on the scale look so similar to her with the context of pastoralist setting where the majority of the women were illiterate despite of our effort: training of field investigators, translation, monitoring and supervision. As a recommendation, the developed tool would be a valid and reliable tool to be used for other researchers and responsible bodies who are interested in mitigating the health problems of the pastoralist community.

\section{Background}

Family planning (FP) allows individuals and couples to attain their desired number of children through spacing and limiting by using contraceptives and treatment of infertility. It also enhances the health of the mother as well as her child [1]. Its use associated with lowering the rates of maternal and infant mortality [1, 2]. According to the WHO report of 2018, even though the use of modern contraceptives reaches 54\% (worldwide) and $28.5 \%$ (Africa), still $24.2 \%$ of women age $15-49$ years had an unmet need for modern contraception [1]. However, such a figure would be very high in the pastoralist community including Afar region, Ethiopia. According to the Mini EDHS,2019 the contraceptive prevalence rate (CPR) in the region was $(12.7 \%)$, and far below the national coverage (41\%). And nearly two-in-ten (17\%) women in the region had an unmet need for FP and total fertility rate (TFR) of 5.5 [3] However, almost all $(89.2 \%)$ women in the region ever heard of any modern contraceptive $[3,4]$. Besides, ther small pocket studies in the region reported that the CPR range from 5.4 to $8.5 \%$ [5-7].

In the Pastoralist community, Afar region, women felt that they are embedded in strong cultural and religious perspectives which promotes a high number of children, discouraging utilizing FP, high male dominancy and women had restricted power to control over their lives including FP use. This was exemplified by early marriages, pregnancy, delivery and a considerable number of women live in a polygamous marriage - $[3,5,7]-$, poor infrastructure, and poor access to contraceptive $[5,6,8]$. Hence, it would be vital to narrow the gap between the knowledge about FP and actual use of FP by devising a tailored tool that considers the multifaced problem which affects the actual use of FP. In an area with low CPR, high unmet need for FP and high TFR, women face a multifaced problem for not use of FP. Hence, addressing the women's knowledge, attitude, perceived male involvement, intention, their belief about whether most people approve or disapprove of the behavior, personal belief to successfully perform the FP use would be vital. Previous literature showed that having positive attitudes play a very important role in increasing FP use. It was cognizant that, women who had a positive attitude more likely to use FP than their counterparts [7]. Moreover, husband objection for not use of FP mention as a potent factor for having low FP coverage in the area [7]. Therefore, it would be vital and timely to address the multidirectional factors which affect FP use in the pastoralist community with context base, reliable and valid tool. Moreover, previous research did not take all these factors (women's knowledge, male involvement, and constructs of IBM) together into a single tool of FP in the setting like the Pastoralist community in Ethiopia. Along with, we have a dearth of evidence on a reliable and valid tool that considers the multifaced factors which hinder the pastoralist women to use FP.

Furthermore, other researchers including us, need an accurate, reliable and valid tool for the hypothesized intervention: community-based intervention in increasing FP use in the pastoralist community. Therefore, this study intends to develop a reliable and valid tool with a pastoralist context to measure the effect of our intervention on the ground. Moreover, it will act as input for other researchers, non-governmental organizations (NGOs) and higher officials who are interested in mitigating the problem of the pastoralist community by averting the morbidity and mortality of the mother as well as her child through FP.

\section{Methods}

We developed a pool of items on FP based on an extensive review of published articles in related topics in general and in the pastoralist community in particular. The 
tool consisted of three parts; (1) 13 knowledge items (2) 12 items of the perceived male involvement on FP and 73 items on perception (items of an integrated behavioral model (IBM)). The IBM items contain expressional and instrumental attitude, subjective norm, intention to use, self-efficacy and perceived control. Tool development passes a lot of steps. To mention its process, in the beginning, experts in reproductive health and Health education assured the face and content validity of the tool using two-panel discussions. Items that were not relevant were dropped while those reported as not clear were re-worded. On the next step, the tool was piloted in $10 \%$ (90 women) of the sample. Items with negatively worded were reversed scored. And reliability test also was done and items with low-reliability value (Cronbach alpha $<0.7)$ were excluded from the list. Exploratory factor analysis was conducted to select relevant constructs. For the IBM tool, the total score is the sum of responses summed to get the total score. Items with high scores indicate a more positive relation towards FP use. An extensive revision of the tool was made by removing items with a low score and adding other items. The revised tool was pretested in 5\% (45) of the sample. In the end, reliability test, exploratory and confirmatory factor analysis was done on 891 tools. The data was collected in two phases as a baseline and end-line data. Also, the construct validity (concurrent and discriminant validity) test was checked using EFA.

\section{Study participants, sample size and sampling procedures}

The study employs pastoralist married women of reproductive age group (15-49) years who reside in the Afar region. Married women who were critically ill during the data collection were excluded from the study. A cluster sampling technique was used to approach the study participants. Three districts namely: Kori, Afambo and Mille were included in the study. From each district, 297 married women were approached. The total sample size was proportionally allocated to the selected kebeles (11 from each district). In the end, a systematic sampling technique was used to approach the study participants in the household. Based on the sample fraction, women were selected at equal interval using systematic random sampling.

\section{Data collection procedure}

The tools contain three parts 1) knowledge on FP, 2) perceived male involvement on FP use, 3) IBM related items: intention to use, subjective norms, self-efficacy, perceived control, expressional and instrumental attitude. The tool was piloted in $10 \%$ of the sample after it was developed by reviewing different literature. The collected piloted tool was exposed to a reliability test. Then, the reliable tool was done for exploratory and confirmatory factor analysis. After all necessary modifications followed the piloted test, the tool was pretested in $5 \%$ of the sample. Modifications were made based on the pretest finding. As the tool was initially developed in English; it was translated to the local language ("Amharic") and back-translated to English to ensure consistency. Twoperson who were blind to each other was used in the translation and back-translation process. The expert on reproductive health, health behavior and promotion including the researcher were analyzed the translation of each item critically and checked the compatibility of the translated items. The tool composed of positively and negatively worded items to indicate the respondent's agreement or disagreement. Items in one category example, knowledge towards family planning use had the same scored. Pastoral married women were approached in the household settings and oral consent to participate in the study was sought. Before interviewing the married women, the data collectors explained the purpose of the study, sampling procedure, ways of data collection (open data kit (ODK)), right not to respond to all or segment of the questionnaire and assured the participant's response's and the response would be kept strictly confidential, no one except the research member would have access. To collect the data six clinical nurses and two supervisors with MPH degrees were used. The training was given for data collectors and supervisors. Data were collected using an open data kit (ODK) a mobile-based application.

\section{Measurement}

Intention to use of FP is defined as the motivational factors that influence a given behavior where the stronger the intention to perform the behavior, the more likely the behavior will be performed. A total of 8 items with response scored 1(uncertain /Disagree) to 3(Certain/ Agree). All the responses of intention to use FP were added together to produce one combined score. Besides, perceived male involvement in FP was collected using 12 items with a response category ranging 1 (Disagree) to 3(Agree). Hence, its responses were added together to produce one combined score.

The items or constructs of integrated behavioral models (IBM): expressional and instrumental attitude, subjective norm, self-efficacy and perceived control were developed and conceptualized to the pastoralist setting. All the components of IBM had two components: direct and indirect measurement. Expressional Attitude (EA) or affect is the married woman's emotional response to the idea of performing the behavior (FP use). Eight items with response categories ranging from 1(unlikely/unworthy) to 3(likely/worthy) were used. Instrumental attitude (IA) or cognitive is the married women's evaluation for the FP use. It was determined by belief about the outcomes of behavior (FP use). Sixteen items response categories ranging from 1(uncertain /unlikely) to 
3(Certain/likely) was used. Subjective norm (SN) is the belief about whether most people approve or disapprove of the behavior (FP use) in their community. With a response scored 1(uncertain /unlikely) to 3(Certain/likely) was used to collect twenty-two items. Perceived control $(\mathrm{PC})$ is a married woman's perceived control over behavioral performance (FP use). Ten items were scored from 3(highly/agree) to 1(doesn't matter/disagree) was used. Self-efficacy (SE) is the personal belief that married women can successfully perform a specific action (FP use) under specified conditions. It was measured with 7 items. Responses were coded as 1 (disagree) and 3 (Agree) $[9,10]$.

Furthermore, the indirect measurement (IM) for the items of subjective norm, expressional and instrumental attitude had a belief and evaluation components. Multiplying the belief response with its corresponding evaluation was made to create a continuous variable. And, the multiplied items of the response were summed up. Along with this, the response of self-efficacy and perceived control was added to form a continuous variable. It should be noted that the IBM constructs had a direct measurement (DM) with a value ranging from 2("poor/low") to 2("good/high"). Hence, a total of 12 (EA), 4 (IA), 17 (SN), 5 (PC) and 4(SE) tool was used. Finally, a correlation test of the DM with its corresponding IM was calculated to assess the importance of the IM to measure the IBM constructs related to FP use in the pastoralist setting.

\section{Data quality control}

To assure the quality of the collected data the following points 1) training for data collectors and supervisors 2) strong supervision at the field 3) an electronic mobilebased application (ODK) was used. Along with, in the pastoralist area where the majority of the married women unable to read and write a simple sentence they may face difficulty in realizing the difference between one item to another. However, a maximum effort was done by the data collectors to encourage her to ask for any ambiguity in the items and to clarify the item based on her view. Hence, additional clarification on the items was done in the case of any deviation from the right content of the tool.

\section{Data analysis}

To analyze the data AMOS of SPSS 22 for windows (SPSS Inc. Version 20., Chicago, Illinois) and R software version 3.6.1 was used. Accordingly, the data were analyzed for 1) face and content validity,2) reliability test 3 ) factor analysis 4) independent sample t-test and correlation test.

\section{Face and content validity}

The face and content validity were done based on expert opinions of reproductive health (4) and health behavior and promotion (1) specialists who have experience in family planning research and pastoralist community. In the beginning, an effort was made to experts to have clear expectations and understanding about the tool development. Apanel discussion was made with the experts to forward their constructive comments for the enrichment of the drafted tool. Hence, to facilitate smooth communication and a high response rate in the tool development, a face to face approach through an expert panel meeting was organized. At the first step (face validity) of the developed tool was given to the experts to look at the items and agreed the tool was valid to measure FP in the pastoralist context. The second step (content validity) of the tool was assured by answering the question of whether the developed tool of FP fully measures or assess the FP issue in the pastoralist context. And, the experts are requested to critically review the domain of the tool. The comments and suggestions of the experts regarding the developed tool were documented and extensive revision was made. As a result, necessary modification to ensure the developed tool readability, clarity, and comprehensiveness was done. In the end, the revised version of the tool was distributed to the expert to add their additional suggestion and to reach an agreement in the developed tool. As a consequence of the discussion few points were raised. Hence, a revised version of the tool was developed after a necessary modification and corrective action was made.

\section{Reliability}

It was determined using the internal consistency test. The internal consistency was calculated using Cronbach's Coefficient Alpha. A Cronbach's alpha higher than 0.7 was considered as reliable items [31]. All items of the tool were separately subjected to reliability test and items were dropped till the Cronbach alpha coefficient was found to be greater than 0.7 to indicate the presence of acceptable consistency of items.

\section{Factor analysis}

In the whole process of our tool development, we employ exploratory and confirmatory factor analysis. It was cognizant that the exploratory factor analysis (EFA) was used in the earlier process of tool development, whereas confirmatory factor analysis (CFA) was used in the later phase of tool development to assess the factorial structure found in EFA and after the underlying structure has been established. Also, used for instrument development and validation to explain the result with good quality [11]. 


\section{Exploratory factor analysis (EFA)}

We used EFA to differentiate the unique and common variance and as a precursor to the confirmatory factor analysis (CFA) in scale development. For each item of the IBM constructs as well as the other indicators, EFA was done. Since it has no a priori restriction it was used to identify the pattern of relationship between the IBM constructs and other indicators to the latent variable. To identify the relevant indicators to be included in our tool adequate sample size (891) was included in our final model. Before factor analysis, the Kaiser-Meyer-Oklin (KMO) measure of sampling adequacy and Bartlett test of sphericity were calculated to check the suitability of the data for the factor analysis [12]. The Kaiser-MeyerOlkin (KMO) index was checked to assess the adequacy of the sample size, which was $\geq 0.84$, indicating an adequate sample size. KMO measure of sampling adequacy measure varies between 0 and 1 and values closer to 1 are better, if it is greater than 0.5 then one can proceed for EFA. Bartlett's Sphericity test along with its chisquare was significant $(P<0.001)$, which verify the existence of sufficient correlation (coefficient greater than 0.4) among the items confirming of factorability of the correlation matrix. Along with this, the correlation matrix was assessed for multicollinearity (coefficient greater than 0.9 ) and singularity (coefficient $=1$ ) of items. Subsequently, multiple approaches were used in synergy to assist the decision on the number of relevant factors. Firstly, to the factor selection or determining the number of factors to be retained in the tool eigenvaluebased procedures; Kaiser-Guttman rule, parallel analysis, and scree plot were used. Factors with an eigenvalue of 1.0 and above were retained for further investigation. According to the Kaiser-Guttman rule, the eigenvalue less than 1.0, describes the variance explained by a factor that is less than the variance of a single indicator. Secondly, each of the eigenvalues of the factors was plotted and inspected to find a point at which the shape of the curve changes direction and becomes horizontal, with the point of shift indicating the number of factors. Thirdly, only the factors that explained a total cumulative variance of $60 \%$ and above were retained. As a factor extraction method, the principal axis factor (PAF) was used as being free of distributional assumption and being less prone to an improper solution than the maximum likelihood (ML) method [11]. Apart from this, direct oblimin rotation with a delta value of zero was used with the assumption of factors are allowed to intercorrelate and helps to avoid misleading solution [12]. Also, it is a is preferred rotation mechanism because it provides a more realistic representation of how factors are interrelated and it produces the same solution as an orthogonal solution in a situation where the factors uncorrelated. Items with a factor loading less than 0.4 were eliminated from the list of tools whereas an item with a factor loading above 0.4 was selected for the final selection of the scales. And items cross-loading above 0.40 were deleted [13]. The appropriate name was given by the researcher for the retained items following their factors. Along with doing EFA, a construct validity (discriminant and convergent) was checked. An EFA results of factor loading of at least 0.40 , no cross-loading of items above 0.40 was revealed discriminant validity, whereas an eigenvalue of 1 and a loading of at least 0.40 will satisfy the criteria of convergent validity [14].

\section{Confirmatory factor analysis (CFA)}

Confirmatory factor analysis (CFA) used in the later phases of scale/tool development to explain the result with good quality and to assess the factor structure found in EFA. Besides, $t$ requires a strong empirical foundation to guide the specification of the model. In the CFA, factor rotation was not specified as it's the nature of fixing crossloading factors to zero. The result of CFA was summarized using indices: Root Mean Square Error of Approximation (RMSEA), Standardized Root Mean Square Error of Approximation (SRMSEA), Comparative Fit Index (CFI) and Tucker- Lewis Index (TLI). In addition to the above indices, a Normed chi-square $(\times 2 / \mathrm{df})$ also used. The cut value for the indices differed across different literature. Accordingly, we use the following cut-value to determine the goodness fit of our model. With this in mind, RMSEA lower than 0.08, SRMSEA less than 0.08, CFI greater than or equal to 0.90 , TLI greater than or equal to 0.95 and chi-square (normed chi-square) with lower value was considered as a significance test and goodness of fit in the CFA $[13,15]$.

\section{Independent t.test and correlation test}

Independent sample $\mathrm{t}$-test was used to find the difference in mean of perceived male involvement, subjective norm, self-efficacy, perceived norm, expressional and instrumental attitudes between FP users and non-users. In addition to the independent test, Cohen's $d$ was calculated. Cohen's d is an appropriate effect size for the comparison between two means. A d of 1 indicates the two groups differ by 1 standard deviation (SD) and with 2 d's value indicates a 2 SD difference. Its value ranges from 0 to infinity: $\mathrm{d}=0.2$ (a 'small'), $\mathrm{d}=0.5$ ('medium') and $d=0.8$ (a 'large') effect size. This means that if two groups' means don't differ by 0.2 standard deviations or more, the difference is trivial, even if it is statistically significant [16]. It was cognizant that, Pearson $r$ correlation with its 95\% CI was used to assess the correlation of the direct and indirect constructs of IBM. The Pearson $r$ correlation has a value ranges from -1 to $1:+$ 1 (strong), +0.5 (positive correlation), 0 (weak correlation) 
and -1 (strong negative correlation), -0.5 (negative correlation) [17].

\section{Results}

A total of 891 married women were included in the analysis of the reliability and validity of the tool. The mean age of the respondents was $26.7( \pm 6.4)$ with a range of 33 years, while it was $34.7( \pm 10.1)$ for their husband. Above three fourth, 688(77.2\%) of the participants were unable to read and write a simple sentence, while $221(77.2 \%)$ of the married women living in a polygamous marriage. Four hundred sixty-one (51.7\%) of the respondents reside within a 1-h distance to the nearest health facility. Above one third (34.6\%) and 495(70.4\%) of the respondents had an average of 3-4 children and a short birth interval for their last consecutive birth, respectively. Above two-in-ten (21.8\%) of the respondents had a history of abortion in their lifetime. The current use of family planning (FP) accounts for 167(18.7\%). A considerable number of 369(41.4\%) and 514(65.2\%) did not have ANC visits for their last pregnancy and gave birth at home, respectively. A considerable number $687(77.7 \%)$ married women want to have more children for the future (Table 1).

\section{Face and content validity}

The content validity of the FP tool was done through an extensive panel discussion with experts on reproductive health and health education and promotion. In the beginning, an effort was made to experts to have clear expectations and understanding about the tool development. On the next steps, four reproductive health specialists and one health behavior and promotion professionals which have experience in family planning research and pastoralist community were selected. Hence, to facilitate smooth communication and high response in the tool development, a face to face approach through an expert panel meeting was organized. Hence, the experts are requested to critically review the domain of the tool. The experts forward their constructive comment in two phases for the development of the tool.

\section{Factor analysis}

In the factor analysis, both exploratory and confirmatory factor analysis was used. Initially, exploratory factor analysis (EFA) was done, then to confirm the developed constructs to measure the intended result confirmatory factor analysis (CFA) was done. Before factor analysis, Kaiser-Meyer-Oklin (KMO) and Bartlett test of sphericity were calculated. And we found that KMO value greater than or equal to 0.84 and Bartlett test of sphericity of $(p<0.00)$ for all items. This shows the variables in the different items were positively correlated with each other and a condition satisfactory to carry out factor analysis (Table 2). As illustrated in the parallel analysis scree plot for intention to use of FP it provides a visible insight. The line seems to begin to level off before the second component and it is beyond factor analysis of simulated and resampled data. It depicts that the first component should be retained and interpreted. And it is a predominant factor for intention to use of FP (Fig. 1).

\section{Exploratory factor analysis}

In the beginning, an exploratory factor analysis (EFA) for the FP tool was conducted. Thirteen items were used to measure the knowledge of the respondent towards FP use. The tool had 64.92 variances explained and Cronbach alpha of 0.85 . The items of intention to use of FP, expressional and instrumental attitude explained variance of $87.75,69.83$ and 63.98 , respectively. For the selfefficacy and perceived norm, a total of 7 and 10 items which explained variance of 66.95 and 78.91, respectively was used (Table 2).

The scale-based factor loading for the knowledge perceived male involvement and construct of the IBM was described below. For instance, knowledge had three components namely: Knowledge on FP side effect, purpose and benefit. These components should be retained and interpreted. Besides, perceived male involvement had one predominant factor (Table 3). Moreover, the construct of IBM shown in (Tables 4 and 5).

\section{Confirmatory factor analyses of FP related tools}

Confirmatory factor analysis was done for the developed tool following the EFA. Acceptable values of the fitness indices were obtained. For example, Knowledge towards FP had normed chi-square of 4.5, RMSEA with $90 \%$ CI of 0.064(0.056,.0.71), SRMR of 0.039, CFI of 0.969 and TLI of 0961 was obtained (Table 6).

Figure 2 shows the flow diagram of the model of the four factors: expressional and instrumental attitude, perceived control and self-efficacy. The minimum and maximum coefficients of the item-scale relationship were 0.45 and 1.1. Moreover, all coefficients of item-scale relationship in the confirmatory factor analysis were significant $(p<0.001)$, that all items were significantly correlated with their factor (Fig. 2).

\section{Mean differences on FP tool for users and non users of contraceptives}

As a result, the below table indicates that there was a significant difference in the mean of users and nonusers on perceived male involvement and constructs of the IBM (expressional and instrumental attitude, subjective norm, self-efficacy, perceived control and intention to use of contraceptive). Besides, Cohen's d was calculated 
Table 1 Basic characteristics of the pastoralist married women: $(n=891)$

\begin{tabular}{ll}
\hline Variables & Number \\
\hline Maternal age ${ }^{\text {a }}$ (years) & $26.74( \pm 6.45)$ \\
Husband age ${ }^{\text {(years) }}$ & $34.74( \pm$ \\
& $10.08)$
\end{tabular}

Able to read and write a simple

Yes

203(22.8)

No

688(77.2)

Are you a single wife to her husband

Yes

670(75.2)

No

$221(24.8)$

Distance to the nearest health facility

Less than $1 \mathrm{~h}$

461(51.7)

$1 \mathrm{~h}$ and above

$430(48.3)$

Number of current children

$1-2$

277(34.8)

3-4

275(34.6)

$5+$

238(29.9)

History of having an abortion $(n=808)$

Yes

$176(21.8)$

No

632(78.2)

Birth interval for their last consecutive birth

Short

495(70.4)

Optimal

208(29.6)

Current use of Family planning

Yes

167(18.7)

No

724(81.3)

Place of delivery for the last child $(n=788)$

Home

$514(65.2)$

Health facility

274(34.8)

ANC visit for their last recent pregnancy

No ANC visit

369(41.4)

$1-3$ visit

277(31.1)

4 and above

245(27.5)

Want to have another child for the future

Yes

$687(77.7)$

No (undecided, no more and says she cannot pregnant)

${ }^{\mathrm{a}}$ Mean (SD)

for all constructs to calculate the effect size. For instance, Cohen's $d$ ranges from 0.5 to 2 for perceived control and intention to use FP, respectively. Moreover, for the constructs of IBM, the correlation coefficient with its 95\% confidence interval was calculated. And the value ranges from 0.6 to 0.7 which shows a higher correlation between the measurement between the direct and indirect measurement (Table 7).

\section{Discussion}

Our study provides a valid and reliable tool for FP in the pastoralist context. The tool contains the following items: knowledge, perceived male involvement and constructs of integrated behavioral model (IBM) (expressional and instrumental attitude, subjective norm, perceived control, self-efficacy and intention to use of FP). Our result achieved by collecting a questionnaire from 891 married women and passes a lot of steps: piloting, pretesting and collecting the actual data. Therefore, the adapted and developed tool could be used in the pastoralist context to measure FP use. And our study finding generalizability will go to a similar pastoralist married women (15-49 years).

As part of our analysis Kaiser-Meyer-Olkin (KMO) test was done to assess the sample size adequacy. And we found the value of 0.84 and above for all items. Even though, its value ranges from 0 to 1 , as the value $>0.5$ it indicates a green light for EFA. Along with, Bartlett's Sphericity test result with its chi-square value revealed a significant $(P<0.001)$ for all items results in the sample size analysis sufficient for factor analysis or sufficient correlation among the items confirming of factorable of the correlation matrix $[12,18]$. Furthermore, the total variance explained was ranged from $58.64 \%$ (subjective norm) to $87.75 \%$ (intention to use of FP) with Cronbach's Alpha coefficient of the scale of 0.81 and 0.97 , respectively was considered as a good tool and can be deployed for research purpose. It should be noted, these results revealed that the scale has internal consistency and its homogeneity to assess the intended measurement is adequate [18].

The constructs of IBM are suitable in the area where the participant's behaviors (FP use) influenced by different circumstances in their surroundings. For example, the pastoralist women are embedded with strong cultural and religious perspectives in which almost all indicators of health including FP use highly influenced by relatives, husband, cultural and religious perspectives (traditional birth attendants (TBA), clan and religious leader). The health indicators of the pastoralist community are very low and not comparable with the national coverage. For instance, the contraceptive prevalence rate based on the min EDHS of 2019 was $12.7 \%$ whereas the national average was $41 \%$ [4]. This implies more effort is needed in understanding why the pastoralist women not utilized FP and why the community prefers a high number of children by examining all-around factor which hinders them. Hence, to assure the deep-rooted reason for having very low CPR, high unmet need and high 
Table 2 Number of items, Cronbach alpha and variance explained of the FP tools, $(n=891)$

\begin{tabular}{llllll}
\hline Variable & $\begin{array}{l}\text { Number of items [Min, } \\
\text { Max] }\end{array}$ & $\begin{array}{l}\text { Cronbach } \\
\text { alpha }\end{array}$ & $\begin{array}{l}\text { Variance } \\
\text { explained }\end{array}$ & $\begin{array}{l}K^{*} O^{*} \\
\begin{array}{l}\text { Bartlett's Test of Sphericity (Chi-squre } \\
(\mathrm{df}))\end{array}\end{array}$ \\
\hline Knowledge & $13[15,38]$ & 0.85 & 64.92 & 0.91 & $6997(78)^{* *}$ \\
Intention to use of FP & $8[8,24]$ & 0.93 & 87.75 & 0.84 & $\left.9248(28)^{* *}\right)$ \\
Perceived Male involvement & $12[12,36]$ & 0.97 & 80.98 & 0.95 & $15,290(66)^{* *}$ \\
Expressional attitude & $10[7,45]$ & 0.76 & 69.83 & 0.89 & $6191(45)^{* *}$ \\
Instrumental attitude & $16[7,66]$ & 0.80 & 63.98 & 0.85 & $8039(120)^{* *}$ \\
Subjective norm (Injective \& descriptive & $22[15,91]$ & 0.81 & 58.64 & 0.92 & $13,905(231)^{* *}$ \\
norm) & & & & & \\
Perceived control & $10[10,36]$ & 0.949 & 78.91 & 0.91 & $9144(45) * *$ \\
Self-efficacy & $8[7,21]$ & 0.81 & 66.95 & 0.91 & $4617(21)^{* *}$ \\
\hline
\end{tabular}

*KMO Kaiser-Meyer-Olkin; Min Minimum; Max Maximum;** significant at $p$-value 0.05

TFR a local based which is a reliable valid tool would be crucial.

A study in Pakistan on translation, adaptation, and validation of a contraceptive attitude scale found a reliable and valid tool that is feasible to measure the attitude towards contraceptive in the study area [19]. Along with a study in Turkey with the aim of perception scale of barriers to contraceptive use was found a reliable and valid tool. The tool was organized as a cognitive, emotional and social domain [20]. Other studies done elsewhere report a positive relationship between attitude and FP use $[7,21]$. It was cognizant that a high score or positive attitude was directly associated with FP use [22]. Not only attitude but also knowledge on FP, perceived behavioral control and intention towards FP use associated with FP use. Along with a study done in the USA found that the developed tool to measure contraceptive knowledge was reliable and valid [23]. And, a study done in Mekelle found that women who had high knowledge associated with increasing FP use [7]. The other proximate indicators of FP use was the intention to use. As it was measured the motivational factors that influence a given behavior where the stronger the intention to perform the FP use, the more likely the FP use will be performed. Indeed, other studies report that a positive relation appears across the intention to use FP with actual FP use $[24,25]$. Finally, a study in Bale found that FP uses associated with perceived behavioral control over FP use [26]. Above all, our study revealed a valid and reliable tool on knowledge, attitude, intention, and perceived behavior control to measure FP use in the pastoralist context. Undoubtedly, we have a dearth of evidence in measuring FP with detail understanding the cultural, religious and local context. Hence, developing a local based tool in an area with FP utilization ranges from 5.4 to12.7\% - $[4,7]$ - would be crucial for developing tailored intervention to enhance FP use in the area which in turn promotes the health of the mother as well as her child by decreasing maternal and neonatal morbidity and mortality.

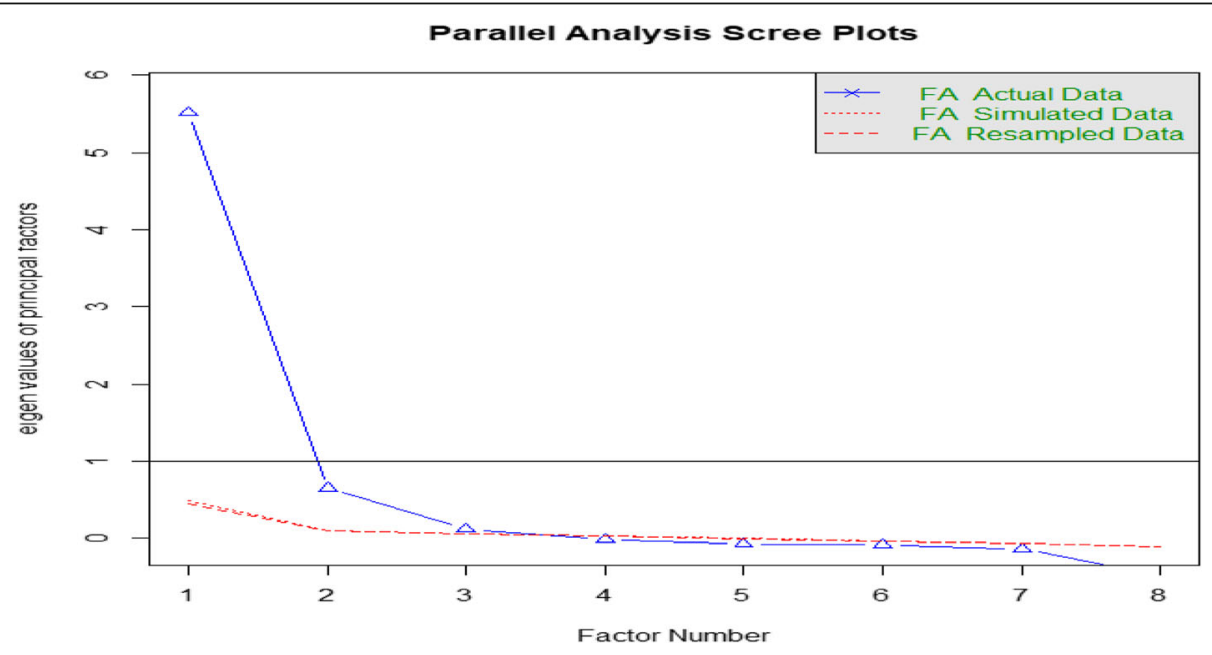

Fig. 1 Parallel analysis scree plot of intention to use of FP 
Table 3 Scale based Factor loading of the knowledge and Perceived male involvement in FP: $(n=891)$

\begin{tabular}{|c|c|c|c|}
\hline & \multicolumn{3}{|c|}{ Factors (F) } \\
\hline & $\mathrm{F}-1$ & $\mathrm{~F}-2$ & $\mathrm{~F}-3$ \\
\hline \multicolumn{4}{|l|}{ Knowledge on the side effect of FP } \\
\hline FP did not have any side effect & .62 & & \\
\hline FP use could cause ministration disturbance & .83 & & \\
\hline FP use could cause heavy bleeding & .83 & & \\
\hline FP could lead to excessive weight gain & .75 & & \\
\hline FP use could prevent daily activity & .74 & & \\
\hline \multicolumn{4}{|l|}{ Knowledge of FP purpose } \\
\hline FP use can prevent HIV/AIDS & & 65 & \\
\hline Family planning has no interference with sexual intercourse or desire & & .70 & \\
\hline Family planning use can cause a cancer & & .59 & \\
\hline There is a family planning can prevent pregnancy for more than 10 years & & .59 & \\
\hline There is a family planning option for men & & .67 & \\
\hline \multicolumn{4}{|l|}{ Knowledge of FP benefit } \\
\hline Family planning improves the health of the mother & & & .80 \\
\hline Family planning improves the health of the child & & & .84 \\
\hline Family planning use can improve the economic status of the household & & & .65 \\
\hline \multicolumn{4}{|l|}{ Perceived male involvement } \\
\hline \multicolumn{4}{|l|}{ If I want to use FP... . } \\
\hline my husband would discuss with me about the need to space childbirth. & .878 & & \\
\hline my husband has ever discussed with me about the need to limit birth childbirth & .898 & & \\
\hline my husband would allow me to discuss with others or attend awareness creation activities on FP & .897 & & \\
\hline my husband would share me important information about FP & .852 & & \\
\hline For me convincing my husband to allow me to use FP may be easy for me & .867 & & \\
\hline If I am going to use FP, I think my husband will allow me to use it & .899 & & \\
\hline My husband has ever involved in the decision to use FP & .898 & & \\
\hline My husband has ever participated in making the choice of the type of FP & .888 & & \\
\hline My husband would handle the domestic activities to let me visit the health facility for FP & .864 & & \\
\hline My husband would provide me financial support to visit the health facility for FP & .932 & & \\
\hline My husband would accompany me to health facility if I want to use FP & .909 & & \\
\hline My husband would remind me the schedule for FP not to forget it. & .899 & & \\
\hline
\end{tabular}

Confirmatory factor analysis was carried for the developed items following the exploratory factor analysis. It was cognizant that, allows for the specification of relationships among the indicator.

uniqueness's (error variances), which may have substantive importance. Its more appropriate than EFA in the later stages of construct validation and the acceptability of the specified model is evaluated by the goodness of fit [11]. However, different works of literature have varied cutoff points for evaluating the model fit. TLI and RMSEA tend to falsely reject models when a small sample size [27] and SRMR don't appear to perform well in a CFA model based on categorical indicators [28]. Accordingly, our study carried out EFA at the initial step followed by CFA. And the result of the model indices was acceptable to conclude the development tool which was examined by EFA and confirmed by CFA.

Our study revealed that a significant difference was found in the mean of users and non-users of FP for all items. A study in Pakistan found that a significant difference in the mean of FP users vs non-user in respective of attitude [19]. Moreover, a study in the pastoralists community of Afar shows that women who had a positive attitude towards FP were more likely to use FP than their counterparts [7]. 
Table 4 Scale based Factor loading of the expressional and instrumental attitude towards FP: $(n=891)$

\begin{tabular}{|c|c|}
\hline Variable & Factor \\
\hline \multicolumn{2}{|l|}{ Expressional attitude } \\
\hline How pleasant you will be if you use family planning? & 0.911 \\
\hline Does limiting the number of children has anything worthy for you? & 0.858 \\
\hline How pleasant if you use family planning for limiting the number of children & 0.855 \\
\hline How comfortable is it, if you use family planning & 0.752 \\
\hline Does the comfort of family planning methods matter for you? & 0.74 \\
\hline How do you feel if you use family planning? & 0.751 \\
\hline How would you feel if family planning methods administered through injection? & 0.706 \\
\hline Does the pain following the use of injectable methods bother you? & 0.69 \\
\hline How important the pleasure you would get if you use family planning & 0.683 \\
\hline How you are concerned with psychological factors following family planning use? & 0.623 \\
\hline \multicolumn{2}{|l|}{ Instrumental attitude } \\
\hline Do you believe that modern contraceptives could improve the health of the mother? & 0.794 \\
\hline Do you believe that modern contraceptives could improve the health of the child? & 0.709 \\
\hline Does the use of family planning make women healthy? & 0.694 \\
\hline Did you believe that frequent birth affects the health of the child? & 0.683 \\
\hline How do evaluate the benefit/s associated to spacing childbirth & 0.668 \\
\hline How do you evaluate the benefit of family planning for delaying pregnancy for you? & 0.657 \\
\hline How limiting the number of children is worthy for you & 0.645 \\
\hline Do you believe that family planning could limit the number of children? & 0.627 \\
\hline Did you believe that frequent birth affects the health of the mother? & 0.597 \\
\hline Do you believe that using modern contraceptives could space childbirth? & 0.574 \\
\hline Do you think modern contraceptive methods are effective to delay pregnancy? & 0.567 \\
\hline How do evaluate having many children for you? & 0.469 \\
\hline How you are wondering about your health associated with giving birth? & 0.640 \\
\hline How you are concerned with the health of women related to childbirth? & 0.613 \\
\hline How frequent you bother about of the health of your children? & 0.560 \\
\hline How giving many children is worthy for you? & 0.447 \\
\hline
\end{tabular}

In our study, the correlation of direct and indirect measurement of the IBM construct ranges from 0.6 to 0.7 which is a high correlation. And the value of the correlation was strong [17]. This implies the indirect measurement of the IBM construct was a good measurement of FP in the pastoralist's community.

\section{Strengths and limitation of the study}

Our study tries to develop a pastoralist context FP tool with a large sample size and homogenous group: marital status, ethnicity, and religion. It deals with a different type of analysis; confirmatory factor analysis to confirm the developed construct intended to measure the topic in the study area. Moreover, the effect size was calculated using Cohen's d instead of reporting using $P$-value only. It was cognizant that $p$-value is a stronger relationship between two variables and tells us than an intervention works. And comparing the developed tool with the main outcome (FP use) provides additional information for the reader and we found a remarkable result. However, an effect size tells us how much it works. We employ only one data collection technique: interview to collect the data. Even though, our study had the abovelisted strength it faces the following limitation. To assure the theoretical constructs (face and content validity), item rated content validity indices (I-CVI) and Scale level validity (S-CVI) were not calculated even though an extensive effort was done to assure the content validity of the tool through a panel discussion with experts. Besides, to minimize the drawback of content validity, content validity was combined with face validity. Assessing a FP issue in an area where the married women embedded with a strong religious and cultural perspective that promotes a high number of children by discouraging women not to utilize FP may lead to stigma and socially desirable response. The other limitation goes to 
Table 5 Scale based Factor loading of the perceived control, self-efficacy and intention to use of FP: $(n=891)$

\begin{tabular}{ll}
\hline Variables & Factor \\
\hline 1) Perceived control & .90 \\
Do you think is there is a risk of discrimination by community members if they know that you are using family planning? & .90 \\
Do you think that possible oppositions from others could influence your decision to use family planning? & .89 \\
How possible discrimination could matter your practice to use family planning? & .87 \\
How possible side effect could matter your to use family planning? & .86 \\
Do you believe that side effect is likely to happen for you following family planning use? & .85 \\
Do you believe that opposition from others is likely to happen consequently to family planning use? & .81 \\
Do you believe that the cost for family planning would worry you if you want to use it? \\
Do you think that the cost of family planning may be expensive if you decided to use it? \\
Do you think that husbands in your community disallow their wives to use family planning?
\end{tabular}

\section{2)Self-efficacy}

If I want to use family planning, I am confident that I can ask and discuss with health providers o how to use it. .90

If want to use family planning, I am certain that I would overcome opposition from others elsewhere.

Though I need to space childbirth, I am not sure that I always can get methods of my choice in health facilities.

It is up to me, If I want to use family planning, I can do it.

If want to use family planning, I am confident to convince your husband that I should use it.

If want to use family planning, I am confident that I always would keep the appointment regarding it. 81

If want to use family planning, I am certain that I would afford the cost for it. 61

\section{3) Intention to use of FP}

At this moment, I can list some of the benefits of FP use I would gain if I use it?

I am happy if I could use FP to space the number of children I would have in the future .90

I am happy if I could use FP to limit the number of children I would have in the future .91

I am willing to use FP to space/limit number of children .88

I have already decided that I should use FP in the near future .86

I have ever used FP in the previous 6 months and I found it relevant me.

I have ever used FP in the past 6 months and I am quite sure I will continue using it in the future. .62

It is expected that women in our community should use FP and so do I

Table 6 Confirmatory factor analyses of FP related tools: $(n=891)$

\begin{tabular}{|c|c|c|c|c|c|c|c|}
\hline Variable & $x^{2}$ & $\mathrm{df}$ & $x^{2} / d f$ & RMSEA $(90 \% \mathrm{Cl})$ & SRMR & $\mathrm{CFI}$ & TLI \\
\hline Intention to use of FP & 258 & 13 & 19.8 & $0.146(0.130,0.161)$ & 0.045 & 0.969 & 0.950 \\
\hline Perceived male involvement & 2266 & 54 & 41.9 & $0.218(0.210,0.226)$ & 0.042 & 0.854 & 0.824 \\
\hline Knowledge on FP & 285 & 62 & 4.5 & $0.064(0.056,0.71)$ & 0.039 & 0.969 & 0.961 \\
\hline Expressional attitude & 534 & 32 & 16.6 & $0.133(0.123,0.143)$ & 0.051 & 0.912 & 0.886 \\
\hline Instrumental attitude & 2310 & 101 & 22.8 & $0.157(0.151,0.162)$ & 0.146 & 0.723 & 0.671 \\
\hline Subjective norm & 2235 & 207 & 10.7 & $0.105(0.101,0.109)$ & 0.075 & 0.844 & 0.826 \\
\hline Perceived control & 1032 & 34 & 30.3 & $0.182(0.171,0.191)$ & 0.041 & 0.891 & 0.856 \\
\hline Self-efficacy & 212 & 14 & 15.1 & $0.126(0.111,0.141)$ & 0.041 & 0.957 & 0.936 \\
\hline
\end{tabular}

$\mathrm{x}^{2} / \mathrm{df}$ Normed chi-square, RMSEA Root Mean Square Error of Approximation, SRMR standardized Root Mean Square Residual, CFI Comparative Fit Index, TLI TuckerLewis Index 


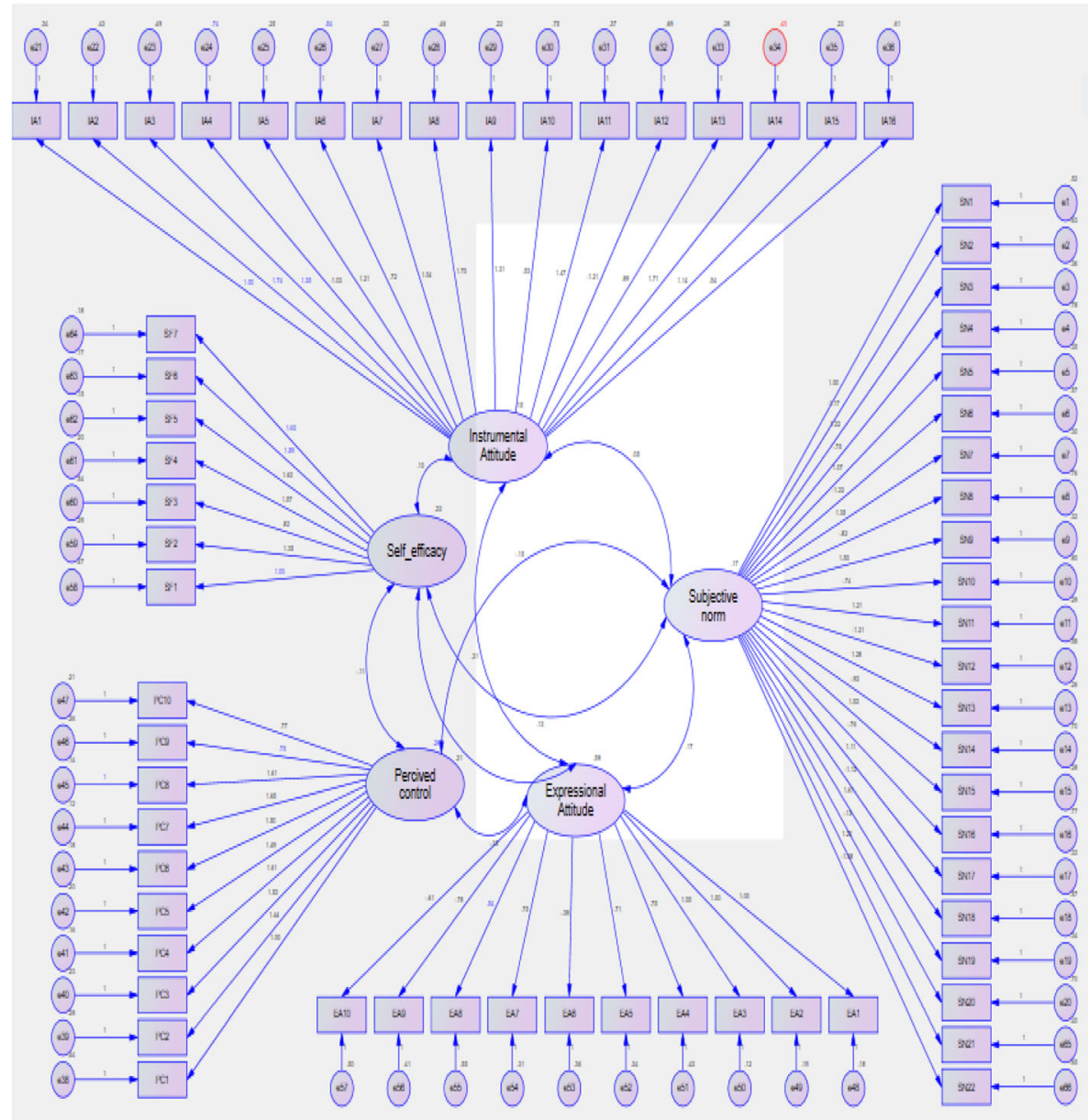

Fig. 2 CFA factor loading

Table 7 Mean, Standard Deviation, t-values and Correlation coefficient for Users and non-Users of FP among Pastoralist married women, Afar, Ethiopia $(n=891)$

\begin{tabular}{|c|c|c|c|c|c|c|c|c|}
\hline \multirow[t]{2}{*}{ Variables } & \multicolumn{2}{|l|}{$\mathrm{FP}$} & \multirow[t]{2}{*}{ t. value } & \multirow[t]{2}{*}{$p$-value } & \multicolumn{2}{|l|}{$95 \% \mathrm{Cl}$} & \multirow[t]{2}{*}{ Cohens'd } & \multirow{2}{*}{$\begin{array}{l}\text { Correlation } \\
\text { coefficient }^{* *} \\
\text { with } 95 \%\end{array}$} \\
\hline & $\begin{array}{l}\text { Non-user } \\
(n=724) \\
\text { Mean }\end{array}$ & $\begin{array}{l}\text { User } \\
(n=167) \\
\text { Mean }\end{array}$ & & & $\begin{array}{l}\text { Lower } \\
\text { level }\end{array}$ & $\begin{array}{l}\text { Upper } \\
\text { level }\end{array}$ & & \\
\hline Knowledge & 27.52 & 20.47 & 12.63 & 0.00 & 5.95 & 8.14 & 1.1 & - \\
\hline Intention to use of FP & 12.94 & 23.20 & 24.53 & 0.00 & 9.44 & 11.08 & 2.1 & - \\
\hline Perceived Male involvement & 21.61 & 30.74 & 11.7 & 0.00 & 7.61 & 10.65 & 1.0 & - \\
\hline Expressional attitude & 21.0 & 34.40 & 15.03 & 0.00 & 11.64 & 15.14 & 1.2 & $0.7(0.66,0.73)$ \\
\hline Instrumental attitude & 40.30 & 57.83 & 13.72 & 0.00 & 15.02 & 20.03 & 1.1 & $0.64(0.60,0.68)^{*}$ \\
\hline Subjective norm & 37.46 & 51.48 & 11.64 & 0.00 & 11.65 & 16.38 & 0.99 & $0.63(0.59,0.67)^{*}$ \\
\hline Perceived control & 22.19 & 25.83 & 6.18 & 0.00 & 2.8 & 4.8 & 0.5 & $0.6(0.56,0.63)^{*}$ \\
\hline Self-efficacy & 14.04 & 17.94 & 11.45 & 0.00 & 3.23 & -4.56 & 0.9 & $0.66(0.62,0.69)$ \\
\hline
\end{tabular}


the difficulty in realizing the difference one item to another, especially when items on the scale look so similar to her with the context of pastoralist setting where the majority of the women were illiterate. Also, To maximize the level of understanding of the items by the respondents, the data collectors encourages the mother to ask for any unclear point about the items, encourage the married women to explain her understanding about the items based on her view and additional clarification on the items was done in the case of any deviation in the level of understanding from the right content of the tool.

Over reporting and under-reporting of the response can affect the reliability of the measure because of the sensitivity of the topic. However, a detailed explanation of the purpose of the study and assured of confidentiality for the collected tool was given to the study participants to minimize the social desirability bias. Our tool doesn't differentiate the descriptive and injective as a component of the subjective norm.

\section{Conclusion}

The findings from this study suggest the developed FP tool was a reliable and valid measure of FP in the pastoralists. Along with it can be used to measure future FP use. However, additional research is warranted to differentiate the component of subjective norm: descriptive and injective and tools with moderate value in the CFA. The indirect measurement of the IBM constructs was a good item to measure FP in the pastoralist community.

\section{Abbreviations}

CFA: Confirmatory factor analysis; CFI: Comparative fit index; CPR: Contraceptive prevalence rate; DFID: Development for international development; EFA: Exploratory factor analysis; EDHS: Ethiopian demographic health survey; FMOH: Federal ministry of health; FP: Family planning; IBM: Integrated behavioral model; KMO: Kaiser-meyer-olkin; RIF: Reproductive innovative fund; RMSEA: Root mean square error of approximation; SRMR: Standardized root mean square residual; TLI: Tucker- Lewis index; TFR: Total fertility rate; WHO: World health organization

\section{Acknowledgments}

We are grateful to thank the data collectors, supervisor and study participants for the successful accomplishment of the study. Besides, we would like to thank the faema leaders, health care providers, and religious leaders participating in the provision of the intervention. Finally, we would like to thank, Afar regional health bureau, Mekelle University, DFID, and $\mathrm{FMOH}$.

\section{Authors' contributions}

MA contributed to the initiation of the study, design, data collection, data analysis, and write up. AAM and AM contributed to the initiation of the study, design, and write up. ER contributed to the interpretation of the findings and write up of the manuscript. All authors read and approved the final manuscript.

\section{Funding}

This study was conducted with the financial support of the Federal Ministry of Health of Ethiopia (FMOH) through the support Development for International Development (DFID through the Reproductive Innovative Fund (RIF) project. The Funders has no role in the design, analysis, and dissemination of the finding

\section{Availability of data and materials}

Our data will be shared and upload as supporting information.

\section{Ethics approval and consent to participate}

The study protocol was approved by the Institutional Review Board (IRB) of Mekelle University College of Health Sciences with a reference number of ERC 1435/2018. Permission was obtained from all relevant authorities in the Afar regional health bureau and participating district health offices. Verbal consent was secured before conducting the interviews. A one-page consent letter was attached to the cover page of each questionnaire as an information sheet which includes a detail description about the purpose of the study, benefit, and risk of participating in the study, participation is voluntary, the right to withdraw from the study, identification of informant was possible only through specific identification numbers and the privacy and confidentiality of collected information.

\section{Consent for publication}

Not applicable.

\section{Competing interests}

The authors declare that they don't have a competing interest.

\section{Author details}

${ }^{1}$ School of Public Health, Mekelle University, College of Health Sciences, Mekelle, Ethiopia. ${ }^{2}$ Graduate School of Public Health, San Diego State University, San Diego, USA.

Received: 20 March 2020 Accepted: 6 August 2020

Published online: 14 August 2020

\section{References}

1. World Health Organization Department of Reproductive Health and Research (WHO/RHR) and Johns Hopkins Bloomberg School of Public Health/Center for Communication Programs (CCP). Family Planning. Global Handbook for Providers Updated 3Rd Edition. Knowledge fo [Internet]. 3rd ed. Geneva: Switzerland; 2018. Available from: https://www.fphandbook.org/ sites/default/files/global-handbook-2018-full-web.pdf.

2. Project P. Futures Group in collaboration with the Centre for Development and Population Activities (CEDPA) and research Triangle Institute (RTI). Strengthening Family Planning Policies And Programs In Developing Countries:An advocacy toolkit. Washington DCDecember 2005.

3. Baschieri A, Cleland J, Floyd SA, Dube A, Msona A, Molesworth A, et al. Reproductive preference and contraceptive use: A comparison of monogamous and polygamous couples in Northern Malawi. J Biosoc Sci. 2013;45(145):22.

4. Sharan M, Valente T. Spousal communication and family planning adoption: effects of a radio drama serial in Nepal. Int Fam Plan Perspec. 2002;28(1):1625. https://doi.org/10.2307/3088271.

5. Shaikh BT, Mazhar SKA. Family planning and contraception in Islamic countries: an annotated bibliography. Germany: LAP Lambert Acadamic Publishing; August 2012

6. Idowu A, Deji SA, Ogunlaja O, Olajide SO. Determinants of intention to use post partum family planning among women attending immunization Clinic of a Tertiary Hospital in Nigeria. Am J Public Health Res. 2015;3(4):6.

7. Nations U. Beijing declaration and platform for action; fourth world conference on women: action for equality. Beijing: Development and Peace; 1995.

8. Bachok N, Abdul Razak A, Ismail NM, Hamzah TNT. Acceptance and Knowledge of Family Planning Among Muslim Women in Rural Villages of Kelantan. J Islam Med Assoc North Am. 2007;39(3):109-16.

9. Central Statistical Agency [Ethiopia] and ORC Macro. Ethiopia Demographic and Health Survey 2005. Addis Ababa, Ethiopia and Calverton, Maryland, USA: Central Statistical Agency and ORC Macro; 2006.

10. Central Statistical Authority [Ethiopia] and ORC Macro. Ethiopia Demographic and Health Survey 2000. Addis Ababa, Ethiopia and Calverton, Maryland, USA: Central Statistical Authority and ORC Macro; 2001.

11. Brown TA. In: Kenny DA, editor. Confirmatory factor analysis for applied research. New York: The Guliford Press; 2006.

12. Field A. Discovering statistics using SPSS. New York, USA: Sage publications Ltd. 2005.

13. AMREF. The "Boma" health delivery model. AMREF: Nairobi; 2013. 
14. CSA. Summary and statistical report of the 2007 population and housing census : population by age and sex composition. Addis Ababa: FDRE population census commission. December 2008. CSA.

15. Bentler PM, Bonett DG. Significance tests and goodness of fit in the analysis of covariance structures. Psychol Bull. 1980;88(3):588-606.

16. Sternberg P. Hubley J. Evaluating men's involvement as a strategy in sexual and reproductive health program. Health Promo Int. 2004;19:389-96. https://doi.org/10.1093/heapro/dah312.

17. Gogtay N, Thatte U. Principles of correlation analysis:statistics for researchers. J Assoc Physicians India. 2016;65:4.

18. Tavşancll E. Attitude measurement and SPSS advanced data analysis. Ankara: Nobel Publisher; 2005.

19. Nosheen I, Jami H. Translation, adaptation, and validation of contraceptive attitude scale. Pak J Psychol Res. 2013;28(2):27.

20. Sen S, Cetinkaya A, Cavuslar A. Perceptıon scale of barriers to contraceptive use: a methodological study. Fertil Res Pract. 2017;3:11. https://doi.org/10. 1186/s40738-017-0038-9.

21. Ying SL. Determinants of Fertility in Malaysia-How Much Do We Know? J Southeast Asian Stud. 1992;23(1):112-32.

22. Chigbu B, Onwere S, Aluka C, Kamanu C, Okoro O, Feyi-Waboso P. Contraceptive choices of women in rural southeastern Nigeria. Niger J Clin Pract. 2010:13:195-9.

23. Bureau UA, Health UPaR, Health EFMo, Health MMo, Health RMo. Three Successful Sub-Saharan Africa Family Planning Programs:Lessons for Meeting the MDGs 2012.

24. $\mathrm{FMOH}$. National Guideline for family planning Services in Ethiopia. Addis Ababa: Federal Democratic Republic of Ethiopia Ministry of Health; 2011.

25. Alemayehu $M$, Belachew $T$, Tilahune $T$. Factors affecting utilization of long acting and permanent contraceptive among married women of reproductive age group in Mekelle Town. BMC Pregnancy Child Birth. 2012; 12, 6 Accessed at http://www.biomedcentral.com/1471-2393/12/6.

26. Alemayehu M, Yebyo H, Medhanyie AA, Bayray A, Fantahun M, Goba GK. Determinants of repeated abortion among women of reproductive age attending health facilities in Northern Ethiopia: a case-control study. BMC Public Health. 2017;17:188. https://doi.org/10.1186/s12889-017-4106-1.

27. Bentler LH \& PM. Cutoff criteria for fit indexes in covariance structure analysis: Conventional criteria versus new alternatives. Struct Equ Model A Multidiscip J [Internet]. 1999;6(1):1-55. Available from: https:/www. tandfonline.com/doi/ref/10.1080/10705519909540118?scroll=top.

28. Gebre-Egziabher D, Medhanyie AA, Alemayehu M, Tesfay FH. Prevalence and predictors of implanon utilization among women of reproductive age group in Tigray Region, Northern Ethiopia. BMC Reprod Health. 2017;14:62. https://doi.org/10.1186/s12978-017-0320-7.

\section{Publisher's Note}

Springer Nature remains neutral with regard to jurisdictional claims in published maps and institutional affiliations.

Ready to submit your research? Choose BMC and benefit from:

- fast, convenient online submission

- thorough peer review by experienced researchers in your field

- rapid publication on acceptance

- support for research data, including large and complex data types

- gold Open Access which fosters wider collaboration and increased citations

- maximum visibility for your research: over $100 \mathrm{M}$ website views per year

At $\mathrm{BMC}$, research is always in progress.

Learn more biomedcentral.com/submissions 